\title{
High-Speed Rail Systems and Tourists' Destination Choice: The Case Study of Naples
}

\author{
Francesca Pagliara \\ Department of Civil, Architectural and Environmental Engineering, University of Naples Federico II, Naples 80125, Italy
}

\begin{abstract}
Tourists have different pictures of their ideal holidays which can be heterogeneous. Market segmentation is the strategic tool to account for heterogeneity among tourists by grouping them into market segments including members similar to each other and dissimilar to members of other segments. An important aspect is the study of the accessibility provided by transport modes which can affect the choice of a given destination for holiday. Transport and tourism are connected, since they represent an important economic activity in most countries around the world. In recent years, major investments on HSRS (high-speed rail systems) have been carried out all around the world. The objective of this paper is to analyse the factors influencing tourists' destination choice and the impact of HSRS in this choice. Tourists, segmented by different socioeconomic characteristics, are analysed together with their different behaviours with respect to the choice of the transport mode, using a recent survey carried out for the city of Naples, south Italy. The main outcome of this study is that several factors affect the choice of this destination and the accessibility provided by a HSR (high-speed rail) link connecting Naples with other Italian cities plays a significant role.
\end{abstract}

Key words: Tourism market, high-speed rail, accessibility, destination choice.

\section{Introduction}

An interesting aspect of the tourism market is to identify the reasons explaining tourists' intention to revisit a specific destination. In this respect, HSR (high-speed rail) might be one of the reasons for tourists to revisit a destination whether this transport alternative is available [1]. Very few contributions are presented in the literatures. The paper written by Seddighi and Theocharous [2] analysed the probability of revisiting Cyprus with respect to socio-demographic and destination characteristics. In this paper, a micro-econometric approach, based on observations of holidaymakers, is proposed. This approach allows the analysis of the characteristics influencing individual travel behaviour. Moreover, it provides a conceptual/methodological framework for the understanding of the nature, form and character of the holiday-decision-making processes of tourists. Another research work analysed the variables influencing the

Corresponding author: Francesca Pagliara, assistant professor, research fields: transport and land use planning. E-mail: fpagliar@unina.it. probability of revisiting Lisbon by using mixed logit models with bounded parameters. The probability of revisiting Lisbon "increases significantly with accommodation range, events, food quality, expected weather, beach, overall quality, nightlife, reputation and safety" [3]. From the literature, it emerged a lack of contributions analysing the relationship between tourism and transport from a quantitative point of view and HSR in particular, except for the contributions by Valeri et al. [4] and Delaplace et al. [5] for the case studies of Rome and Paris and Pagliara et al. [6] for the case study of Madrid.

With more than 46.1 million tourists per year, Italy is the fifth most visited country in the world, behind France (79.5 million), United States (62.3 million), China (57.6) and Spain (56.7 million). People mainly visit Italy for its art, history, fashion and culture, beautiful coastlines and beaches, its mountains and old monuments. Italy also contains more world heritage sites than any other countries in the world. Tourism is one of Italy's growing and most profitable industrial sectors, with an estimated revenue of $€ 136.1$ billion. In 
2013, Italy's tourist industry overall turnover was about $€ 136.1$ billion, thus confirming as an ever expanding sector: contributing to over $8.6 \%$ of GDP (gross domestic product); employing over 1.1 million qualified workers; more than 153,000 firms throughout Italy's regions [7].

The objective of this paper is to analyse the factors influencing tourists' choice of a destination for tourism purpose and the role of HSRS (high-speed rail systems) in this choice. Section 2 describes the case study of Naples. Estimation results of the factors influencing the choice of this destination are highlighted in Section 3, together with the role of HSRS in this choice. A comparison with the case studies of Madrid and Paris is reported as well in this section. Conclusions and further perspectives are reported in Section 4.

\section{Case study of the Tourist Destination in Naples}

In the last few years, Naples, in the south of Italy, has become one of the favorite destinations for all those Italian and foreign tourists who love spending their holidays in cities of artistic interest. This is also due to the opening of the new HSR link at the end of 2005 [8].

Unlike cities in which art is stored in museums and daily life happens on the streets, Naples's distinctive mark is its folklore: People are living and working among the artistic beauties of the city. Tourism has become a key factor in the city's economy. Buildings, churches, streets, ancient fortresses and castles in the sea, as well as natural caves and places impregnated with mystery and mysticism, make Naples unforgettable in the minds of all travellers [9].

An RP (revealed preference) survey was employed from October 28, 2013 to November 28, 2013 and from January 5, 2014 to February 5, 2014. The questionnaire was available on the web and accessible through the following websites: www.tripadvisor.it, www.enit.it and www.turistipercaso.it.

In total, 327 complete questionnaires have been collected and analyzed together with a descriptive and econometric analysis [10].

The questionnaire is made up of three parts:

(1) collection of socio-economic and demographic characteristics of the tourists (e.g., age, gender, marital status, education, employment, residence, income and travel alone/with a group);

(2) collection of information related to the travel (origin, duration, transport mode, willingness to revisit Naples, budget, etc.);

(3) collection of data concerning the use of HSR.

Men represent the majority of the sample (58\%), while women present with $42 \%$. The $59 \%$ of the samples are represented by Italians, while the remaining $41 \%$ are foreigners. Tourists between 21 35 years old are 38\% and between 41 60 years old are $35 \%$. The $45 \%$ of the tourists are singles while $55 \%$ have partners. The $83 \%$ travel in group, mainly with friends $(27 \%)$ or with the partners $(22 \%)$. The majority has a degree $(60 \%)$, while $38 \%$ go to the high school. A detailed analysis of the socioeconomic characteristics is shown in Table 1.

The most chosen transport mode has been HSR, as reported in Table 2, followed by plane, train, car and bus.

Concerning the factors influencing the choice of Naples as destination (see Table 3), tourists are mainly attracted by its gastronomy $(29.56 \%)$ and by its historical heritage (24. 53\%).

\section{Models on the Probability of Visiting and Revisiting a Destination by HSR for Tourism Purpose}

The results of the survey have been used to estimate some regression models with the aim of computing the factors, influencing the probability of revisiting Naples and the role of HSR on this (Model 1) and the probability of using HSR for visiting cities close to Naples (Model 2) for tourism purpose.

A micro-econometric approach based on observations of tourists is here proposed to examine the characteristics influencing the individual travel behavior. 
Table 1 Socioeconomic characteristics of the tourists.

\begin{tabular}{|c|c|}
\hline Tourists & Percentage \\
\hline Italians & $59 \%$ \\
\hline Foreigners & $41 \%$ \\
\hline \multicolumn{2}{|l|}{ Gender } \\
\hline Man & $58 \%$ \\
\hline Woman & $42 \%$ \\
\hline \multicolumn{2}{|l|}{ Marital status } \\
\hline Single & $45 \%$ \\
\hline$\underline{\text { Partnered }}$ & $55 \%$ \\
\hline \multicolumn{2}{|l|}{ Age } \\
\hline$<21$ & $6 \%$ \\
\hline $21 \sim 35$ & $38 \%$ \\
\hline $36 \sim 40$ & $11.3 \%$ \\
\hline $41 \sim 60$ & $34.6 \%$ \\
\hline$>60$ & $10.1 \%$ \\
\hline \multicolumn{2}{|l|}{ Level of education } \\
\hline Junior school & $1.8 \%$ \\
\hline High school & $37.6 \%$ \\
\hline University degree & $60.6 \%$ \\
\hline \multicolumn{2}{|l|}{ Professional status } \\
\hline Employee & $58.7 \%$ \\
\hline Unemployed & $8.3 \%$ \\
\hline Freelance & $5.5 \%$ \\
\hline Manager & $5.2 \%$ \\
\hline Student & $13.1 \%$ \\
\hline Retired & $9.2 \%$ \\
\hline \multicolumn{2}{|l|}{ Income } \\
\hline$<500$ & $22.6 \%$ \\
\hline $500 \sim 1,500$ & $24.2 \%$ \\
\hline $1,500 \sim 2,500$ & $22.9 \%$ \\
\hline $2,500 \sim 3,500$ & $19.9 \%$ \\
\hline $3,500 \sim 4,500$ & $4.9 \%$ \\
\hline$>4,500$ & $5.5 \%$ \\
\hline \multicolumn{2}{|l|}{ Travelling } \\
\hline Alone & $17 \%$ \\
\hline With relatives & $34 \%$ \\
\hline With friends & $27 \%$ \\
\hline With partners & $22 \%$ \\
\hline \multicolumn{2}{|l|}{ Accommodation's type } \\
\hline B\&B/hostel & $18 \%$ \\
\hline Relatives and friends & $17 \%$ \\
\hline Hotel & $51 \%$ \\
\hline Other & $4 \%$ \\
\hline \multicolumn{2}{|l|}{ Trip arrangement } \\
\hline Friends/relatives & $3.4 \%$ \\
\hline By myself & $78.9 \%$ \\
\hline Travel agency & $17.7 \%$ \\
\hline
\end{tabular}

Source: author's elaboration.
Table 2 Transport mode.

\begin{tabular}{lc}
\hline Transport mode & Total \\
\hline HSR & $41 \%$ \\
Car & $10 \%$ \\
Plane & $31 \%$ \\
Bus & $7 \%$ \\
Train (not HSR) & $11 \%$ \\
\hline
\end{tabular}

Source: author's elaboration.

Table 3 Factors influencing the choice of Naples as a tourist destination.

\begin{tabular}{lrll}
\hline $\begin{array}{l}\text { Factors influencing the choice } \\
\text { of Naples }\end{array}$ & \multicolumn{1}{c}{ Total } & Men & Women \\
\hline Gastronomy & $29.56 \%$ & 51.06 & 48.94 \\
Good quality of promotion & $8.18 \%$ & 38.46 & 61.54 \\
Cultural and artistic heritage & $24.53 \%$ & 61.54 & 38.46 \\
Shopping and events & $11.95 \%$ & 36.84 & 63.16 \\
Less expensive with regard to & $8.18 \%$ & 61.54 & 38.46 \\
other destinations & & & \\
Presence of relatives and friends $10.06 \%$ & 37.50 & 62.50 \\
HSR & $4.40 \%$ & 57.14 & 42.86 \\
Other & $3.14 \%$ & 20.00 & 80.00 \\
\hline
\end{tabular}

Source: author's elaboration.

It provides a conceptual framework for understanding the nature and type of the holiday-decision-making processes of individuals. Specifically, the use of a logistic regression model has been considered.

The literature on logistic regression is large and rapidly growing since 1970 . Proposed to overcome the limitations of ordinary least square regression in handling dichotomous outcomes [11], this methodology was consolidated overtime and has became an integral component of any discrete data analysis [12]. Models using logistic regression have been extensively applied to tourism demand analysis [13], especially when studying the decision to go/not to go on holidays.

In the simplest case where there is one predictor variable $X$ only and one dichotomous outcome variable $Y$ (binary case), the logistic model predicts the logit of $Y$ from $X$ [11]. With reference to qualitative response variables, as in our case, logistic regressions generate the probability to observe a given aspect $(k)$ of $Y$ given $X(\mathrm{P}(Y)=k / X$ or $\pi k(X))$, following a binomial distribution of the error term. 
The logistic regression specification is reported in the following:

$$
\ln \left(\frac{\pi}{1+\pi}\right)=\alpha+\beta_{1} x_{1}+\beta_{2} x_{2}+\ldots+\beta_{k} x_{k}
$$

with

$$
\begin{gathered}
\pi=\operatorname{Probalility}\left(Y=\text { outcome-of-interest } \mid X_{1}=x_{1},\right. \\
\left.X_{2}=x_{2}, \ldots, X_{k}=x_{k}\right)=\left(\frac{e^{\alpha+\beta_{1} x_{1}+\beta_{2} x_{2}+\ldots+\beta_{k} x_{k}}}{1+e^{\alpha+\beta_{1} x_{1}+\beta_{2} x_{2}+\ldots+\beta_{k} x_{k}}}\right)
\end{gathered}
$$

where, $\pi$ is the probability of the outcome $Y, \alpha$ is the intercept parameter, $\beta_{k}$ is the vector of the $s$-slop parameters and $X_{s}$ are the set of predictors. The variables here considered in Models 1 and 2 are the ones that have turned out to be significant, i.e., $t$-student test greater than 1.96 after calibration with the use of the software SPSS. Therefore:

- Model 1:

Predicted logit $($ REVISIT $=1)=\beta_{0}+\beta_{1 \text { NATION }}+$ $\beta_{2 \text { MARRIED }}+\beta_{3 \text { FREELANCE }}+\beta_{4 \text { LESS-EXP }}+\beta_{5 \text { EVENTS }}+$ $\beta_{6 \text { GASTRONOMY }}+\beta_{7 \text { CULT-ART_HERITAGE }}+\beta_{8 \text { HSR }}$ where:

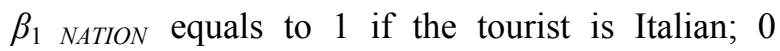
otherwise;

$\beta_{2}$ MARRIED equals to 1 if the tourist is married; 0 otherwise;

$\beta_{3 \text { FREELANCE }}$ equals to 1 if the tourist is a freelance; 0 otherwise;

$\beta_{4 \text { LESS-EXP }}$ equals to 1 if the tourist has chosen to revisit Naples since it is less expensive with regard to other destinations; 0 otherwise;

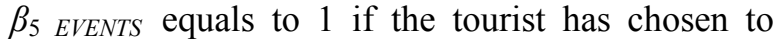
revisit Naples because of the presence of events (sport. music. etc.); 0 otherwise;

$\beta_{6 \text { GASTRONOMY }}$ equals to 1 if the tourist has chosen to revisit Naples because of its gastronomy; 0 otherwise;

$\beta_{7 \text { CULT-ART_HERITAGE equals to } 1 \text { if the tourist has }}$ chosen to revisit Naples because of its cultural and artistic heritage ; 0 otherwise;

$\beta_{8 H S R}$ equals to 1 if the tourist has chosen to revisit Naples because of the presence of HSR; 0 otherwise;

- Model 2:
Predicted logit $($ HSR_NEAR_CITIES $=1)=\beta_{0}+\beta_{1 \text { NATION }}$

$+\beta_{2 \text { STATION_ACCESS }}+\beta_{3 \text { TRAVEL-TIME }}+\beta_{4 \text { SERV-FREQ }}$

$$
+\beta_{5 \text { SAFETY }}+\beta_{6 \text { CONFORT }}
$$

where:

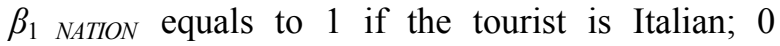
otherwise;

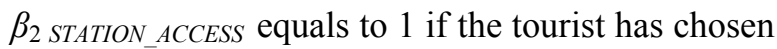
HSR because of the departure/arrival station accessibility; 0 otherwise;

$\beta_{3}$ TRAVEL-TIME equals to 1 if the tourist has chosen HSR because of the reduction of travel time; 0 otherwise;

$\beta_{4 \text { SERV-FREQ }}$ equals to 1 if the tourist has chosen HSR because of the service frequency; 0 otherwise;

$\beta_{5 \text { SAFETY }}$ equals to 1 if the tourist has chosen HSR because it is safe; 0 otherwise;

$\beta_{6 \text { CONFORT }}$ equals to 1 if the tourist has chosen HSR because of the comfort; 0 otherwise.

In the first model, the dependent variable is the probability of revisiting Naples (Yes: 1; No: 0). Estimation results are reported in Table 4.

The model presents a good ability of reproducing available data and an index of that is represented by $\rho^{2}=0.462 ; \rho_{\text {adj }}^{2}=0.452$. A value of $\rho^{2}$ equal to 1 means that the model has a perfect ability of reproducing the available data. All the parameters are significant and of the expected sign since $t$-student is greater than 1.96. The variable HSR is significant and has a positive impact on the probability of revisiting Naples. The tourist who has the highest probability of

Table 4 Probability of revisiting Naples for tourism purpose: estimation results.

\begin{tabular}{lc}
\hline Variable & Coefficient $(t$-test) \\
\hline Constant & $0.324(8.602)$ \\
Nation & $0.056(2.588)$ \\
Married & $-0.118(-2.986)$ \\
Freelance & $-0.094(-2.090)$ \\
Less expensive & $0.851(23.142)$ \\
Events (sport, music, shopping, etc.) & $0.880(16.872)$ \\
Gastronomy & $0.145(3.879)$ \\
Cultural and artistic heritage & $0.901(32.716)$ \\
HSR & $0.107(2.310)$ \\
\hline
\end{tabular}


Table 5 Probability of visiting cities close to Naples by HSR for tourism purpose: estimation results.

\begin{tabular}{ll}
\hline Variable & Coefficient $(t$-test $)$ \\
\hline Constant & $0.044(3.455)$ \\
Nation & $0.035(2.058)$ \\
Station access & $0.266(10.191)$ \\
Travel time & $0.530(20.410)$ \\
Service frequency & $0.315(7.530)$ \\
Safety & $0.272(6.327)$ \\
Comfort & $0.229(7.213)$ \\
\hline
\end{tabular}

revisiting Naples is Italian, not married, not a freelance, and he/she chooses Naples because it is less expensive with respect to other destinations. Naples offers a lot of events in terms of sport, music and shopping, but the reason why tourists want to come back is the cultural and artistic heritage of the city. In the second model, the dependent variable is the probability of choosing HSR for visiting cities close to Naples (Yes: 1; No: 0). Table 5 reports the estimation results for Model 2.

Also, this model has a good ability to reproduce available data $\left(\rho^{2}=0.493 ; \rho_{\text {adj }}^{2}=0.485\right)$. All the attributes are significant and of the expected sign. The tourist with the highest probability of visiting cities close to Naples by HSR is Italian, and he/she chooses HSR because of the accessibility to the departure/arrival station, because of the reduction of travel time, because of the frequency of the service. Safety and comfort are also factors that affect this choice.

The analysis of the probability to revisit Paris and Madrid has provided very different results [6].

Estimation results are reported in Table 6. In the case of Madrid, the model presents a high explanatory power indicating that the model fits the sample data pretty well. All the parameters are highly significant (except "transport cost" $>€ 700$ and HSR is variable, which are not significant) even though they have the expected sign. Indeed, the satisfaction of past experience ("first-time Madrid") has a positive impact on the probability to revisit Madrid. With reference to the socio-economic characteristics, the Spaniards have a higher probability to revisit Madrid for tourism purposes.

Transport characteristics seem not to have a big impact on the destination choice. Indeed, although the transportation cost has the correct sign, it is not significant, meaning that it is not an attribute relevant in destination choice. Nevertheless, the quality of promotion of heritage resources is important. The main outcome from the Madrid case study is that tourists will

Table 6 Variables influencing the probability of revisiting Madrid and Paris for tourism purpose [6].

\begin{tabular}{lll}
\hline Variable & \multicolumn{1}{c}{ Coefficient $(t$-value $)$} \\
\cline { 2 - 3 } & Madrid & Paris \\
\hline Age $18 \sim 24$ & - & $0.105(1.979)$ \\
Married & $-0.063(-2.315)$ & - \\
Freelance & $0.104(2.2040)$ & - \\
Nation & $0.121(3.633)$ & $0.192(3.904)$ \\
University & - & $0.238(5.111)$ \\
First-time Madrid & $-0.083(-2.809)$ & - \\
Stay relative's home & $0.111(2.131)$ & - \\
Travel with friends & - & $0.167(3.063)$ \\
HSR* & $-0.015(-0.552)^{*}$ & $0.177(4.167)$ \\
Transport cost* $>€ 700$ & $-0.028(-0.954)^{*}$ & - \\
Visit relatives & - & $0.160(3.416)$ \\
Architect & $-0.559(20.409)$ & $0.434(9.712)$ \\
Multi-destinations & - & $0.172(3.677)$ \\
Event & - & $0.0902(2.036)$ \\
$\rho^{2}$ & 0.493 & 0.650 \\
$\rho_{\text {adj }}^{2}$ & 0.485 & 0.595 \\
\hline
\end{tabular}

\footnotetext{
* Not significant.
} 
Table 7 Variables influencing the probability of visiting cities close to Madrid and Paris by HSR for tourism purpose.

\begin{tabular}{lll}
\hline Variable & \multicolumn{1}{c}{ Coefficient $(t$-value $)$} \\
\cline { 2 - 3 } & Madrid & Paris \\
\hline Nation & $-0,140(-2,249)$ & $0.108(2.417)$ \\
Income $0 \sim 2,500$ euros & - & $0.084(1.954)$ \\
Total holidays 7 days & - & $-0.425(-7.443)$ \\
Stay Paris 5 days & - & $0.238(4.589)$ \\
Total holidays cost & - & $-0.257(-2.792)$ \\
Easy to near cities & $0.296(5.101)$ & $0.289(5.822)$ \\
Safety & $0.273(4.547)$ & - \\
Service frequency & $0.328(4.317)$ & - \\
Ticket cost & $-0.359(-6.921)$ & - \\
Comfort & $0.456(10.658)$ & - \\
Station access & $0.398(7.419)$ & - \\
$\rho^{2}$ & 0.631 & 0.41 \\
$\rho_{\text {adj }}^{2}$ & 0.594 & 0.392 \\
\hline
\end{tabular}

revisit the city irrespective on the presence of the HSR.

In the case of Paris, all the attributes are significant and have expected sign. Tourists that are willing to revisit Paris are younger than the average. They are French, aged between 18 and 24, and were at the university when they were surveyed. They travel with friends, and they would like to go back to Paris because of its architectural sites, the opportunity of visiting other places from there and the possibility of visiting relatives. Paris is also a city full of events, and this is a factor influencing the choice to come back, particularly for the youth. The HSR variable is very significant and positive, meaning that, for the young people, the presence of HSR influences their choice. The variable itself embeds all the characteristics connected with HSRS, i.e., high speed, reduction of travel times, high frequency, reliability, easy access to the station and so on. Moreover, young people know that reduced fares are available, so they can benefit from this fact to come back.

The second model intends to identify which variables have an impact on the use of HSR to travel from Madrid or Paris towards nearest cities served by HSR. The variables are described below, and the estimation results are reported in Table 7.

In the case of Madrid, all the attributes have the expected sign and are significant: the probability to reach nearby cities by AVE (Alta Velocidad Espagnola) ("easy to near cities"), the accessibility of departure/arrival station ("station access"), travel comfort ("comfort"), service frequency, and safety have a positive impact on the probability to use HSR service to visit cities located nearby. The cost of transportation ("ticket cost") has a negative impact. Foreign tourists are using HSR more frequently than national ones to move to cities close to Madrid by HSR. This fact is confirmed by the negative sign of the variable "nation".

In the case of Paris, the average tourists that will likely visit cities close to Paris by HSR are French with income below $€ 2,500$ per month, and are going to stay in Paris less than 5 days out of a trip 7 days long. They will choose TGV (Train à Grande Vitesse) because of the easy access to two nearby cities connected by it, and their total cost for the holiday is less than 1,000 euros.

Consequently, the role of HSR in the probability of visiting other cities is different in Madrid compared to Paris. In Madrid, this is for foreigners, while in Paris this is for French people.

\section{Concluding Remarks}

Several factors influence the choice of a tourist, like the presence of architectural sites, the quality of 
promotion of the destination itself, the presence of events, etc. HSR system also plays a role in this choice, but in a different way. In France, HSR is considered as a real alternative transport mode. Therefore, as the results of the models, French tourists choose it for moving around France for their holidays. However, in the case study of Spain, tourists have a different perception of HSR, because the models show that they are willing to revisit Madrid regardless of the presence of HSR. Despite this trend, the analysis suggests that foreigner tourists in Madrid choose HSR for visiting cities close to Madrid. The results for Madrid are similar to the case of Rome. Naples and Paris are very similar case studies, since the Italian tourists are affected by the presence of HSR in choosing this destination for their holidays, as well as for visiting cities close to it.

Further investigation is necessary to understand the specific role of HSR system on tourism in other countries, inside the same countries or in other cities and especially intermediate cities. However, these findings provide useful information for analysts in their efforts to target specific tourist segments and to identify the way by which HSR can impact tourism as reasons. A greater awareness of tourists' characteristics with respect to a given destination represents an important input for improving packaging and promotion.

\section{References}

[1] Pagliara, F., Vassallo, J. M., and Román, C. 2012. "High Speed vs. Air Transportation: The Madrid Barcelona Case Study." Journal of the Transportation Research Board 2289: $10-7$
[2] Seddighi, H. R., and Theocharous, A. L. 2002. "A Model of Tourism Destination Choice: A Theoretical and Empirical Analysis.” Tourism Management 23: 475-87.

[3] Barros, C. P., and Assaf, A. G. 2012. "Analyzing Tourism Return Intention to an Urban Destination." Journal of Hospitality \& Tourism Research 36: 216-31.

[4] Valeri, E., Pagliara, F., and Marcucci, E. 2012. "A Destination Choice Model for Tourism Purpose." Presented at the ASRDLF 2012 Conference Special Session on High Speed Rail, Tourism and Territories, Belfort, France.

[5] Delaplace, M., Pagliara, F., Perrin, J., and Mermet, S. 2014. "Can High Speed Rail Foster the Choice of Destination for Tourism Purpose?." Procedia - Social and Behavioral Sciences 111: 166-75.

[6] Pagliara, F., Delaplace, M., and Vassallo, J. M. 2014. "High-Speed Train and Tourists: What is the Link? Evidence from the French and the Spanish Capitals." Presented at the Urban Transport Conference, Faro, Portugal.

[7] Pagliara, F. 2014. High Speed Rails Systems: Impacts on Mobility, on Tourism and on Mobile Workers. Saarbrücken: LAP Lambert Academic Publishing.

[8] Cascetta, E., Papola, A., Pagliara, F., and Marzano, V. 2011. "Analysis of Mobility Impacts of the High Speed Rome-Naples Rail Link Using Within-Day Dynamic Mode Service Choice Models." Journal of Transport Geography 19: 635-43.

[9] Pagliara, F., and Papa, E. 2011. "Urban Rail Systems Investments: An Analysis of the Impacts on Property Values and Residents' Location." Journal of Transport Geography 19: 200-11.

[10] Spagnuolo, A. 2014. "The HSR Systems and the Toursim Market: The Case Study of Naples." Master dissertation, University of Naples Federico II. (in Italian)

[11] Peng, C. Y., and So, T. S. H. 2002. "Logistic Regression Analysis: A Premier." Understanding Statistics 1: 31-70.

[12] Agresti, A. 2002. Categorical Data Analysis. New York: Wiley.

[13] Witt, S. F., and Witt, C. A., 1995. "Forecasting Tourism Demand: A Review of Empirical Research.” International Journal of Forecasting 11: 447-75. 